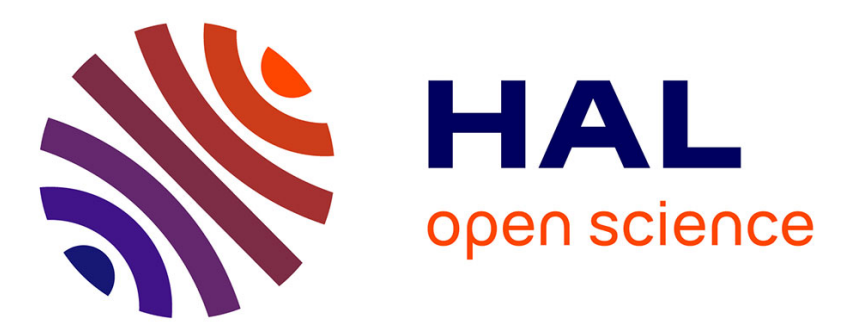

\title{
Factors for Effective Learning in Production Networks to Improve Environmental Performance
}

\author{
Alexander Schurig, Mélanie Despeisse, Eric Unterberger, Steve Evans, \\ Gunther Reinhart
}

\section{- To cite this version:}

Alexander Schurig, Mélanie Despeisse, Eric Unterberger, Steve Evans, Gunther Reinhart. Factors for Effective Learning in Production Networks to Improve Environmental Performance. IFIP International Conference on Advances in Production Management Systems (APMS), Sep 2015, Tokyo, Japan. pp.697-704, 10.1007/978-3-319-22756-6_85 . hal-01417636

\section{HAL Id: hal-01417636 \\ https://hal.science/hal-01417636}

Submitted on 15 Dec 2016

HAL is a multi-disciplinary open access archive for the deposit and dissemination of scientific research documents, whether they are published or not. The documents may come from teaching and research institutions in France or abroad, or from public or private research centers.
L'archive ouverte pluridisciplinaire HAL, est destinée au dépôt et à la diffusion de documents scientifiques de niveau recherche, publiés ou non, émanant des établissements d'enseignement et de recherche français ou étrangers, des laboratoires publics ou privés.

\section{(c)(1)}

Distributed under a Creative Commons Attribution| 4.0 International License 


\title{
Factors for effective learning in production networks to improve environmental performance
}

\author{
Alexander Schurig ${ }^{1,3}$, Mélanie Despeisse ${ }^{1}$, Eric Unterberger ${ }^{2}$, Steve Evans ${ }^{1}$, Gunther \\ Reinhart $^{3}$ \\ ${ }^{1}$ Institute for Manufacturing, University of Cambridge, 17 Charles Babbage Road, Cambridge, \\ CB3 OFS, United Kingdom \\ ${ }^{2}$ Fraunhofer IWU Project Group Resource-efficient Mechatronic Processing Machines, Beim \\ Glaspalast 5, 86153 Augsburg, Germany \\ ${ }^{3}$ Institute for Machine Tools and Industrial Management, Technische Universität München, \\ Boltzmannstrasse 15, 85748 Garching, Germany \\ \{mas254, md621\}@cam.ac.uk, eric.unterberger@iwu.fraunhofer.de
}

\begin{abstract}
There is evidence that the environmental performances of factories operating under similar circumstances vary greatly, even within one company. This indicates that production sites are operated in different ways which suggests a potential for improvement. Previous research shows that collaboration within production networks can improve factory performance. Learning collaboratively across factories is a promising approach to reduce the environmental impact of production sites. Several companies recognised this opportunity. Processes and systems to support knowledge and know-how exchange within their production network are already in place. In this research a literature review and interviews were carried out to explore factors that influence learning between factories. Such factors are critical to develop an effective tool enabling learning across factories and thus environmental performance improvements.
\end{abstract}

Keywords: Interfactory learning $\cdot$ Environmental performance $\cdot$ Learning collaboratively

\section{Introduction}

Multinational production companies typically operate around the world. Factors - such as factory history, size, location, implemented production processes, or type of products manufactured-influence the measurable characteristics of each factory [1], [2].

On the one hand certain factors differ immensely across factories within a company and impact the factories' environmental performance, which is defined as the "measurable results of an organisation's management of its environmental aspects" [3]. For instance, older sites in a production network are built and equipped according to decade-old standards while more recently built sites follow contemporary standards and 
adopt newer, more efficient technologies. Some might be specialised in energy intensive manufacturing whereas others might focus on assembly. On the other hand several aspects, such as production processes, produced products or location, can be used to find clusters of factories operating under virtually equal circumstances [4], i.e. similar products, production technology and scale. However, the environmental performances of such factories vary even though they operate under comparable conditions. One reason for these variations can be an asymmetry of knowledge and know-how between factories. This asymmetry implies a potential for knowledge and know-how transfer as well as for learning. As a consequence the interaction of employees in and across factories to learn collaboratively can improve the environmental performance of the factories. Learning between factories, or interfactory learning, is a promising approach to reduce the environmental impact of factories. In this context, the research presented in this paper has three objectives:

- To find examples of systems, processes and tools already in place to support interfactory learning (knowledge and know-how exchange).

- To understand factors that hinder and amplify the learning as well as knowledge and know-how exchange between factories.

- To identify the requirements and specifications for a tool to effectively support interfactory learning for environmental performance improvement.

\section{Methods}

This research was conducted in two stages. First, the three objectives were addressed by undertaking a literature review in the field of learning and knowledge and knowhow exchange Second, interviews conducted with three companies were analysed. Section three presents and discusses three core arguments for this study:

1. Environmental performance varies between factories operating in akin conditions.

2. A difference in performance is a potential for learning.

3. Learning collaboratively can improve factories' performance.

The interview partner's companies operate in the following sectors: pharmaceutical, automotive supply and aerospace industry. All companies employ more than 80.000 people and operate factories around the world. The interviewed expert of the aerospace company is the leader of a network of people responsible energy efficiency in manufacturing. In the pharmaceutical company two interviews were conducted. First an environment, safety and health (ESH) manager of a big plant with around 8.000 employees took part in the semi structured interview. Second a member of an internal committee that advises both the executive committee as well as the board of directors in ESH matters participated. Furthermore an ESH manager as well as an energy manager of an automotive supplier offered their answers. The interviewees are part of the personal network of the researchers. All the companies they work for are certified according to ISO 14001 which means that learning and knowledge exchange activities are ongoing. Furthermore it was important that the companies operate several factories around the 
world in order to examine interfactory learning. The chosen industries as well as the different positions of the interview partners allow comprehensive insights into how companies deal with learning as well as knowledge and know-how exchange across factories on different levels.

\section{Performance Variation as Potential for Learning}

Environmental performance variations can be perceived as an indicator pointing towards potential for learning within a company's network of factories. When factories operate under similar circumstances an asymmetry in knowledge regarding environmental performance improvements can lead to such differences. Researchers found that learning within a single factory and within a network of factories influences site performance positively. Thus, interfactory learning is a promising approach to improve the environmental performance of factories within a network.

Variation in factories' environmental performance. Several groups of researchers have investigated environmental performance in various sectors (e.g. electronics, metal and dairy products) and have shown that there is a strong variation in performance between factories or farms. In the electronics industry, Nagel assessed 25 production facilities (13 in the USA, 7 in Europe, 4 in Asia, 1 in Canada) of printed board suppliers. Using data submitted by the suppliers the author calculated a normalized indicator. The results of the calculations and the submitted data showed that the environmental performances of the facilities vary. For example, to produce $1 \mathrm{~kg}$ of printed board the „best" supplier used 7.5 times less energy than the "worst" (taking into consideration only suppliers which submitted consistent mass balance data). The author explicitly states that the technology in each facility is comparable [5]. Therefore reasons for the variations can be diverse, including inefficient usage of the equipment or suppliers submitting unreliable data. In another study, Roberts \& Gehrke presented similar results with five companies operating in New Zealand's metal working sector. Based on site visits and interviews with both the companies and local council staff the researchers found two types of correlations between business practice and environmental performance. First, practices that contribute to reducing waste and overhauling faulty equipment directly lead to less impact on the environment. Second, implementing management approaches, such as focusing on product and process quality, ongoing improvement and leadership as well as empowering employees lead to a better resource efficiency [6]. Finally, Van Passel et al. examined farm accountancy data of 41 dairy farms in Flanders, Northern Belgium. The researchers assessed the farms calculating an indicator consisting of economic and environmental aspects. They found two interesting conclusions. One is that well performing farms showed both good economic as well as a good environmental outcomes. The other one is that managers of underperforming farms tend to be older and show potential for additional education [7].

The three studies mentioned above focused on different companies producing similar products with similar production technology. Bocken et al. analysed companies with 
well-established environmental management systems and programs already implemented and running. The researchers found that, despite the environmental management systems in place, the environmental performances of factories within a single company can significantly vary. The reasons for these variations range from systemic to people-related [8]:

- Since every factory normally has a separate environmental management team the multi-site implementation of promising measures is difficult.

- Factories naturally operate in a rather isolated way which can even result in difficulties in circulating success stories in the production network.

- Unequal mind-sets and the varying levels of motivation of people responsible onsite also contribute to the environmental performance variations.

The above studies confirm that it is possible to assess and compare the environmental performance of factories operating under similar circumstances. Only one study deals with the environmental performance variation of factories within one company. However, the results of this study illustrate the potential for improving the environmental performance by exchanging knowledge and know-how as well as learning across factories of one company.

Performance variation to identify potential for learning. According to Senge et al. knowledge is the result of learning. In an organisational context the authors defined learning as "the continuous testing of experience, and the transformation of that experience into knowledge - accessible to the whole organization, and relevant to its core purpose" [9]. It can be concluded that others can use and understand this knowledge because it becomes available for the organisation.

Nonaka argues that organisational knowledge has its origin in individual knowledge, which can be explicit or tacit. Explicit knowledge is easy to share whereas sharing tacit knowledge can be challenging. The author offers insights into how to turn tacit into explicit knowledge [10]. Thus the transformation of experience into knowledge described in the definition above is addressed in this paper.

Learning and knowledge are related in a circular manner. Learning is the process which produces knowledge which again can be the starting point for further learning.

$\mathrm{Su}$ and Chen examined the relationship between two organisational learning mechanisms - conceptual learning and operational learning - and plant performance. Measuring an index based on cost, quality, flexibility and delivery the researchers found that both mechanisms influence the plant performance positively [1]. In other words, a higher quality of learning leads to both a broader knowledge base and a better plant performance. So, in order to improve the environmental performance of a plant one can consider improving the learning within the plant. Other plants that show a better environmental performance can play an important role in this improvement, because their better performance can be linked to a better ongoing learning and thus a broader knowledge base. Differences in the environmental performance of factories point to differences in knowledge and know-how. Thus the variations can be used as an indicator to identify learning potentials. 
Learning collaboratively to improve performance. Vereecke et al. examined eight manufacturing companies operating in different industries and each running four to 10 factories. Sites can, according to the authors, play four different roles in a network: isolated, receiver, hosting network player and active network player. Among other aspects the authors concluded that plants that transfer innovations to others also receive innovations from others in return. Although the mutual exchange of innovations seems to be beneficial for partnering factories, the performance regarding cost, quality or time measures was not connected to the role a factory plays in the network [2]. It is surprising that neither isolated factories struggle to reach expectations nor active network player factories outperform other network participants. That implies that plants do not benefit in participating in the knowledge exchange with other factories. Additionally declaring that factories interact in a network contradicts Bocken et al.'s finding that factories operate rather independently.

However, in a study 10 years later Vereecke and de Meyer reassessed the eight multinationals interviewing managers in headquarters. There are three interesting observations that the authors made:

- First, an expertise transfer from both other factories and headquarters to a factory with the clear objective of improving its performance took place [4]. This contradicts the conclusion of their earlier study that participating in exchanging innovations with other factories has no effect on a factory's performance.

- Second, over time the number of active network players increased. One reason is that companies progressively regard factories as a source of knowledge and knowhow [4]. Hence better performing factories with a broader knowledge base can play an important role in improving the learning of weaker factories.

- Third, active network players can ensure their existence in the long term by creating and sharing knowledge even if it seems unfavourable in the short term [4]. Concluding this reinforces that factories benefit from exchanging knowledge in a network.

In the context of pollution prevention, pollution control and environmental management systems Gavronski et al. advise plant managers to take two aspects into consideration to improve environmental performance: to promote a trustful climate among the staff in the plant and to expand knowledge exchange beyond the borders of the factory itself. For the latter the researchers suggest two forms of engagement. In larger corporations other factories can be approached to exchange knowledge and know-how. Additionally managers can go beyond the borders of the cooperation to contact plants of other companies, e.g. customers or suppliers, but also academic institutions [12]. Vereecke and de Meyer emphasise the positive influence of knowledge exchange in a production network on the economic performance of plants. Gavronski et al. explicitly point out that exchanging knowledge and know-how improves the environmental performance of plants. Therefore both works underline the improvement potential inherent in learning and thought exchange in a production network. 


\section{Interview Results}

The findings on how people learn and exchange knowledge in the environmental context within a company were grouped in clusters as shown in Table 1: individuals, the group they form and the way they interact.

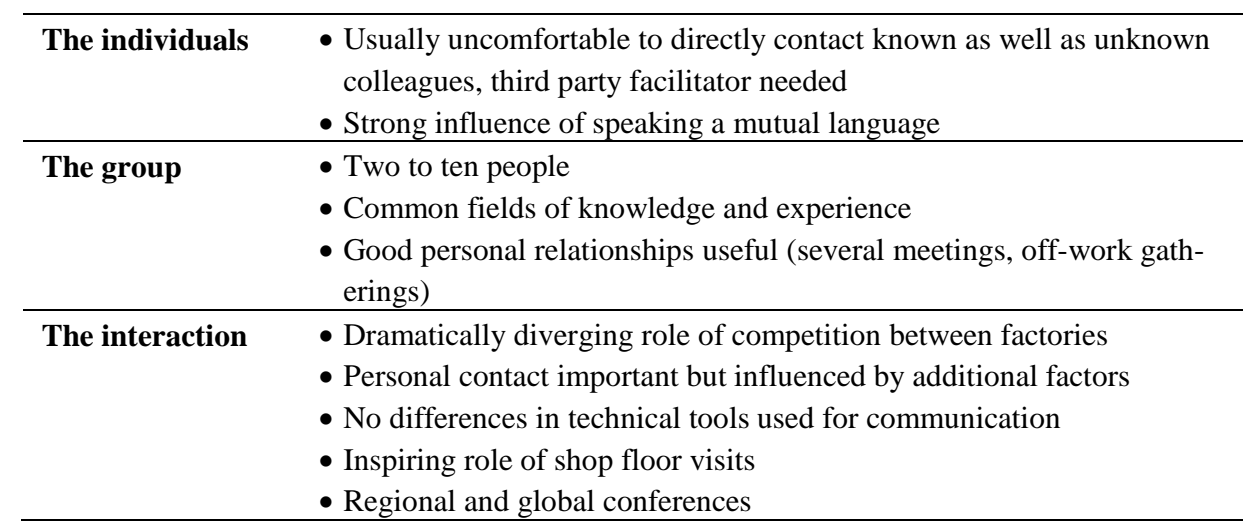

Table 1. Clustered findings of analysis of interviews

The individuals. All interviewed employees agreed that direct contact between colleagues in different factories needs to be facilitated or even enforced by a third party of the company. Providing contact details together with project descriptions does not comfort employees. Whereas not speaking the same language is a major hindrance, speaking the same language is a major amplifier for exchange and learning.

The group. Best learning occurs in rather small groups of two to ten people. The three settings illustrated by the interviewees involved pre-selected individuals with matching interests, knowledge and know-how:

- Audit teams can either be composed of employees responsible for the field to be audited in other plants or of dedicated full-time auditors. Mixtures of these two lineups are possible.

- Working groups are established for a limited time and deal with a specific issue that concerns different factories. People who are responsible for that topic in their factory participate in these groups.

- People responsible for the environmental performance of their factory meet up in regular personal meetings with colleagues from other factories throughout the year.

The exchange, collaboration and learning in these contexts is very lively. Good personal relationships influence the collaboration positively. However, to establish such beneficial relationships regular meetings and off-work gatherings are necessary. The longer colleagues know each other the easier it is for them to learn from each other. 
The interaction. Competition affected the companies interviewed in different ways. One company uses competition for making decisions on future investments in a production line for a new product. Thus competition is perceived as a hindering factor for interfactory learning in an environmental context. An interviewee of another company stated that a similar kind of competition might facilitate the cooperation between factories in future and that friendly competition ("Who saves more resources?") already occurs. In the third company at the end of each audit factories receive a school mark. Furthermore the performance of a factory is anonymously compared to other factories.

Face-to-face interactions between employees generally supports collaboration between factories. Nevertheless factors, such as varying openness of learning partners, trust, sympathy, etc. influence the exchange.

There are no decisive differences in the technological communication means the companies use to support collaboration and exchange. However, in general it is hard to access the right information in the correct situation, e.g. using a good practice database.

Shop floor visits play a major role in the interactions. The environment has a stimulating influence. In one case after visiting several own factories for learning purposes the next workshop will take place at a manufacturer operating in a different industry.

Furthermore all companies organise regional and global conferences as well as workshops to share knowledge and know-how as well as to establish personal networks. One company employs coordinators - hierarchically working between factories and the central functions - in USA, Mexico and China to organise such events.

In one company two major factories collaborate intensively. One reason for this unusually strong exchange is their regular mutual reporting to the top management.

\section{$5 \quad$ Discussion and Conclusion}

Differences in the environmental performance of factories operating under similar conditions lead to a potential for learning collaboratively. While new technologies can be an enabler for learning as they make more information available, finding the right information can be more time consuming. Therefore the direct interaction between colleagues in a suitable context promises to enable learning to happen.

The common testing of experiences and turning subsequent understandings into organisational knowledge supports improvements of factories' environmental impact. The interviews conducted in this study show that companies recognize interfactory learning as a means to improve factories' performance. Processes and systems originating from the field of knowledge management are already implemented and working. This paper discusses the conditions for a favourable learning environment.

The main findings of this study show that learning occurs when the people involved work on a concrete topic, such as an audit or a working group activity on a specific issue. According to the interview findings, effective learning currently takes place when employees with similar work backgrounds exchange experiences in small groups. This is due to the nature of the issues the participants are facing and thus the same good practices can be applied. In contrast conferences bring together people with different 
backgrounds. This may cause discomfort as employees need to directly contact unknown colleagues; it is therefore debatable whether this type of conferences is best to foster interfactory learning. However bringing together people with the same professional background can limit the impact of learning. When backgrounds and views only partly overlap, there is more potential for learning. One of the interviewed companies is using this approach to learn from other industrial sectors and spread the acquired knowledge across its manufacturing sites.

This research is part of a wider project on Environmental Performance Variation (EPV) conducted with the EPSRC Centre for Industrial Sustainability. This work contributes to the EPV project by uncovering factors for effective learning across factories. Based on these factors a tool will be developed to further support interfactory learning and convert it into a more effective means to improve the environmental performance of factories.

\section{Acknowledgements}

We would like to thank Dr. Peter Schnurrenberger, Andreas Peters, Peter Lunt, Marcus Dörr and Till Sieghart for their valuable contributions. We also wish to acknowledge the EPSRC Centre for Industrial Sustainability for their support.

\section{References}

1. Netland, T., Ferdows, K.: What to Expect From a Corporate Lean Program. Sloan Manage Rev 55, 83-89 (2014)

2. Vereecke, A., van Dierdonck, R. de Meyer, A.: A typology of plants in global manufacturing networks. Manage Sci 52(11), 1737-1750 (2006)

3. Perotto E., Canziani R., Marchesi R., Butelli P.: Environmental performance, indicators and measurement uncertainty in EMS context: a case study. J Clean Prod 16, 517-530 (2008)

4. Vereecke, A., de Meyer, A.: The dynamic management of manufacturing networks. Vlerick Leuven Gent Management School, Working Paper Series 2009/15 (2009)

5. Nagel, M. H.: Managing the environmental performance of production facilities in the electronics industry: more than application of the concept of cleaner production. J Clean Prod $11(1), 11-26(2003)$

6. Roberts, L., Gehrke, T.: Linkages between best practice in business and good environmental performance by companies. J Clean Prod 4 (3-4), 189-202 (1996)

7. van Passel, S., Nevens F., Mathijs E., van Huylenbroeck G. : Measuring farm sustainability and explaining differences in sustainable efficiency. Ecol Econ 62 (1), 149-161 (2007)

8. Bocken, N., Morgan, D., Evans, S.: Understanding environmental performance variation in manufacturing companies. Int J Prod Perf Manag 62 (8), 856-870 (2013)

9. Senge, P. M., Kleiner, A., Roberts, C., Ross, R., Smith, B.: The fifth discipline fieldbook: Strategies and tools for building a learning organization. Currency Doubleday, NY (1994)

10. Nonaka, I.: The knowledge-creating company. Harvard Bus Rev 69 (6), 96-104 (1991)

11. Su H. C., Chen Y. S.: Unpacking the relationships between learning mechanisms, culture types and plant performance. Int J Prod Econ 146, 728-737 (2013)

12. Gavronski, I., Klassen, R. D., Vachon, S., Nascimento, L. F.: A learning and knowledge approach to sustainable operations. Int J Prod Econ 140 (2), 183-192 (2012) 